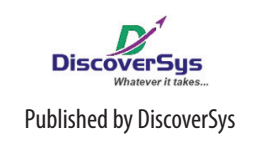

\section{Ledakan pertumbuhan penduduk di Provinsi Bali dan solusinya}

\author{
Dewa Nyoman Wirawan*
}

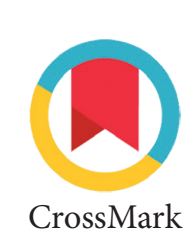

CrossMark
Program Studi Magister
Ilmu Kesehatan Masyarakat, Pascasarjana Universitas Udayana

*Correspondence to: Dewa Nyoman Wirawan, Program Studi Magister Ilmu Kesehatan Masyarakat, Pascasarjana Universitas Udayana

\section{PENDAHULUAN}

\section{Pertumbuhan Penduduk Provinsi Bali}

Berdasarkan hasilSensus Penduduk2010, penduduk Bali berjumlah 3.890.757 jiwa, sedangkan jumlah penduduk pada Sensus Penduduk 2000 adalah 3.146.999. ${ }^{1}$ Dengan demikian dalam 10 tahun jumlah penduduk Bali bertambah sebanyak 743.758 jiwa atau hampir sama dengan penduduk Kota Denpasar pada tahun 2010 yang berjumlah 788.589 jiwa. Secara rata-rata pertumbuhan penduduk Bali dalam periode tahun 2000-2010 adalah $2,15 \%$ per tahun dan termasuk rangking 13 tertinggi di Indonesia dan jauh diatas rata-rata laju pertumbuhan penduduk tingkat nasional sebesar $1,49 \%{ }^{2}$ Bila dibandingkan dengan pertumbuhan penduduk Provinsi Bali sejak tahun 1961, terlihat bahwa pertumbuhan penduduk tahun 2000-2010 adalah paling tinggi (Grafik-1). ${ }^{1}$

Bila dilihat per kabupaten/kota seperti disajikan pada Grafik-2, laju pertumbuhan penduduk (20002010) terlihat amat timpang, yaitu amat tinggi di Kabupaten Badung $(4,62 \%)$ dan Kota Denpasar $(4,01 \%)$ sedangkan di kabupaten lain hanya sekitar 1-1,5\% per tahun. ${ }^{1}$ Bila laju pertumbuhan penduduk kabupaten/kota di Bali masih tetap sama dengan laju pertumbuhan penduduk tahun 2000-2010, maka perkiraan jumlah penduduk Bali Tahun 2020 akan mencapai 4.727.270 jiwa, dimana penduduk Kota Denpasar akan melampaui jumlah 1 juta jiwa (Tabel-1).

Komposisi penduduk Bali hasil Sensus Penduduk 2010 menunjukkan bahwa penduduk laki-laki sedikit lebih banyak dibanding penduduk perempuan. Dari segi ekonomi, kondisi yang perlu dicermati adalah komposisi penduduk menurut umur yaitu penduduk umur 0-14, 15-64 dan 65 tahun keatas. Penduduk umur 0-14 dan umur 65 tahun keatas secara ekonomi biasanya tergantung pada penduduk umur 15-64 tahun. Kota Denpasar mempunyai rasio ketergantungan paling rendah yaitu 39,31, yang artinya setiap 100 penduduk produktif di Kota Denpasar menanggung sekitar 40 orang penduduk non produktif. ${ }^{1}$ Kondisi ini jauh berbeda dengan Kabupaten Klungkung, Bangli dan Karangasem yang mempunyai rasio ketergantungan relatif tinggi. Kondisi ini adalah akibat arus urbanisasi dimana penduduk produktif (umur 15-64 tahun) di Kabupaten Klungkung, Bangli dan Karangasem banyak yang mencari nafkah di Kota
Denpasar sedangkan yang tinggal di daerah asalnya kebanyakan penduduk usia anak-anak (0-14) dan penduduk usia tua (65 tahun keatas). Bila jumlah penduduk dibandingkan dengan jumlah wilayah maka terlihat bahwa kabupaten/kota yang terpadat adalah Denpasar, Badung dan Gianyar. ${ }^{1}$

\section{Tingkat Kelahiran dan Pemakaian Kontrasepsi}

Secara nasional, pada tahun 1991, Total Fertility Rate (TFR) atau Tingkat Kelahiran Total di Indonesia adalah 3,0 (SDKI 1991), kemudian menurun menjadi 2,9 pada tahun 1994 (SDKI 1994), menjadi 2,8 pada tahun 1997 (SDKI 1997), menjadi 2,6 pada tahun 2002 (SDKI 2002) dan 2,6 pada tahun 2012 (SDKI 2012). ${ }^{3}$

Dari data ini (Grafik-3) terlihat bahwa dalam rentang waktu 10 tahun terakhir TFR secara nasional tetap pada tingkat 2,6 (SDKI 2012). Sedangkan untuk Provinsi Bali adalah 2,22 (tahun 1991), 1,89 (tahun 1997), 2,10 (tahun 2002) dan 2,30 (tahun 2012). ${ }^{3}$ Dari data ini terlihat bahwa dalam 10 tahun terakhir TFR (tingkat kelahiran total) di Bali mengalami peningkatan dari 2,10 menjadi 2,30. Seperti telah diuraikan di atas bahwa rata-rata pertumbuhan penduduk Bali dalam 1 tahun dari tahun 1990-2000 adalah $1,26 \%$ sedangkan pada tahun 2000-2010 adalah $2,15 \%{ }^{1,2}$ Peningkatan yang hampir dua kali lipat ini kemungkian disebabkan karena penduduk masuk (migrasi masuk) ke Bali amat tinggi dan juga disertai oleh angka kelahiran yang meningkat dengan asumsi tingkat kematian yang tidak banyak menurun.

Sejalan dengan menetapnya TFR dalam rentang waktu 10 tahun terakhir, proporsi pasangan usia subur (PUS) yang sedang memakai kontrasepsi modern pada saat survei (current contraceptive use) di Bali cenderung mengalami penurunan. Pada SDKI tahun 2007 (Grafik-4), pasangan usia subur (PUS) yang sedang memakai kontrasepsi pada saat survei adalah sebesar $67,2 \%$, pada tahun 2010 menurun menjadi $64,3 \%{ }^{4}$ dan pada tahun 2012 menurun kembali menjadi 59,6\%. ${ }^{3}$ Kecenderungan seperti ini terjadi pula di kebanyakan provinsiprovinsi di Indonesia. Pada SDKI 2012, secara ratarata nasional PUS yang sedang memakai kontrasepsi adalah sebesar $57,9 \%$ dan Bali berada di posisi 15. ${ }^{3}$ Fenomena ini menunjukkan bahwa dalam 10 tahun terakhir pengendalian kependudukan dan 
Tabel 1 Perkiraan jumlah penduduk menurut Kabupaten/Kota tahun 2020, Provinsi Bali

\begin{tabular}{|c|c|c|c|c|}
\hline Kab/kota & $\begin{array}{c}\text { Pertumbuhan } \\
\text { penduduk } \\
\text { thn 1990-2000 }\end{array}$ & $\begin{array}{l}\text { Pertumbuhan } \\
\text { penduduk } \\
\text { thn 2000-2010 }\end{array}$ & $\begin{array}{c}\text { Jumlah } \\
\text { penduduk } \\
\text { tahun } 2010\end{array}$ & $\begin{array}{c}\text { Perkiraan jumlah penduduk } \\
\text { tahun } 2020 \text { bila pertumbuhan } \\
\text { penduduk tahun } 2010-2020 \\
\text { sama dengan thn } 2000-2010\end{array}$ \\
\hline Jembrana & 0,64 & 1,22 & 261.638 & 293.558 \\
\hline Tabanan & 0,73 & 1,14 & 420.913 & 468.897 \\
\hline Badung & 2,33 & 4,64 & 543.332 & 795.438 \\
\hline Denpasar & 3,20 & 4,02 & 788.589 & 1.105 .602 \\
\hline Gianyar & 1,56 & 1,80 & 469.777 & 554.337 \\
\hline Klungkung & 0,31 & 0,95 & 170.543 & 186.745 \\
\hline Bangli & 0,94 & 1,07 & 215.353 & 238.396 \\
\hline Karangasem & 0,49 & 0,96 & 396.487 & 434.550 \\
\hline Buleleng & 0,34 & 1,13 & 624.125 & 694.651 \\
\hline Prov Bali & 1,26 & 2,15 & 3.890 .757 & 4.727 .270 \\
\hline
\end{tabular}

Sumber: BPS Provinsi Bali (Hasil Sensus Penduduk 1990, 2000, dan 2010)

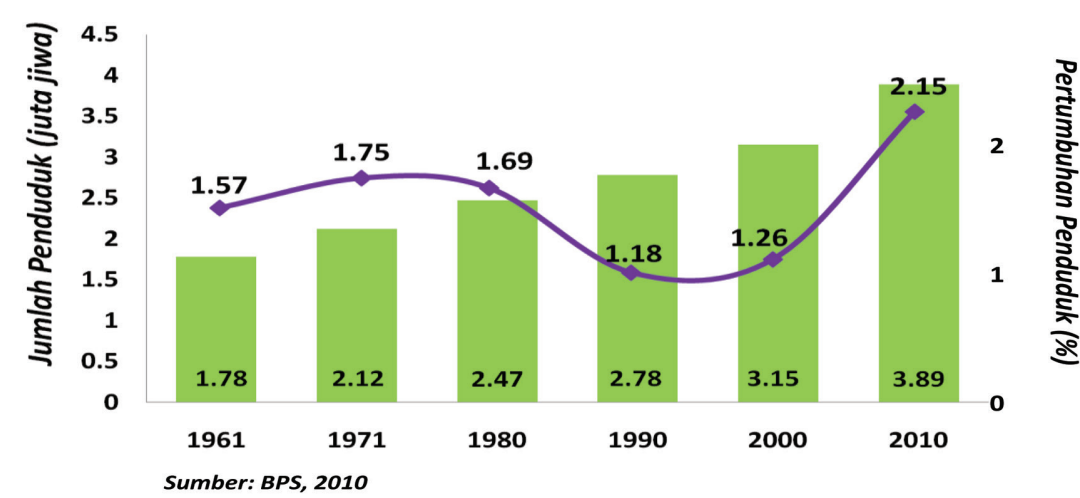

Gambar 1 Jumlah penduduk Bali dan rata-rata pertumbuhan penduduk per tahun sejak tahun 1961-2010

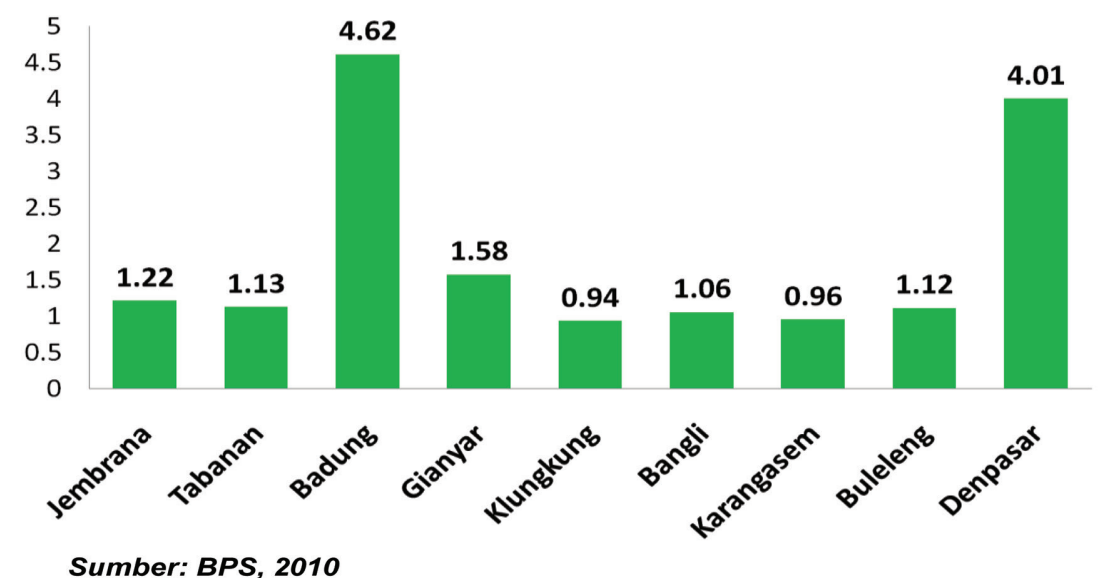

Gambar 2 Rata-rata laju pertumbuhan penduduk per tahun per Kabupaten/ Kota Provinsi Bali periode 2000-2010

kegiatan-kegiatan untuk mengendalikan jumlah kelahiran di Indonesia, termasuk di Provinsi Bali berada dalam keadaan stagnan.

Selain persentase pemakaian kontrasepsi yang menurun, jenis alat atau metode kontrasepsi yang dipergunakan juga cenderung beralih dari metode yang lebih efektif dan jangka panjang ke metode yang tingkat kelangsungan pemakaiannya lebih rendah. Metode yang termasuk jangka panjang adalah tubektomi, vasektomi, IUD dan susuk (implan). Sedangkan metode yang tingkat drop-outnya lebih tinggi adalah suntikan, pil dan kondom. ${ }^{3}$ Pada periode 1982-1985, metode kontrasepsi yang dipakai oleh pasangan usia subur yang sedang memakai kontrasepsi di Bali adalah IUD (70\%), pil (12,5\%), tubektomi (9\%), suntikan (6,5\%) dan kondom (1,5\%)., Sedangkan pada tahun 2012, metode yang dipakai adalah suntikan (36,2\%), IUD $(31,9 \%)$, pil $(15,1 \%)$, tubektomi $(9,4 \%)$, kondom $(4,9 \%)$, vasektomi, KB Susuk dan metode lain $2,5 \% .^{3}$

Dari data di atas, TFR yang meningkat di Bali disebabkan karena pemakaian kontrasepsi yang menurun dan metode yang dipergunakan adalah kebanyakan metode yang tingkat kelangsungannya lebih rendah. ${ }^{3}$ Faktor lain yang juga berpengaruh pada peningkatan TFR adalah tingginya tingkat kelahiran pada wanita usia remaja. ${ }^{3}$

\section{PEMBAHASAN}

Pertumbuhan penduduk yang amat tinggi akan memberikan dampak negatif bagi Bali dalam berbagai aspek kehidupan dan pembangunan, yaitu aspek ekonomi, penyediaan lapangan kerja, saranaprasarana (sekolah, kesehatan, jalan, perumahan, air bersih), alih fungsi lahan, kriminalitas dan masalah sosial lainnya. Disamping pertumbuhannya yang tinggi, ketimpangan antar kabupaten/kota juga amat lebar. Hal ini disebabkan karena terpusatnya sentra-sentra ekonomi di Bali bagian Selatan. Selain karena tingginya migrasi masuk, tingginya 


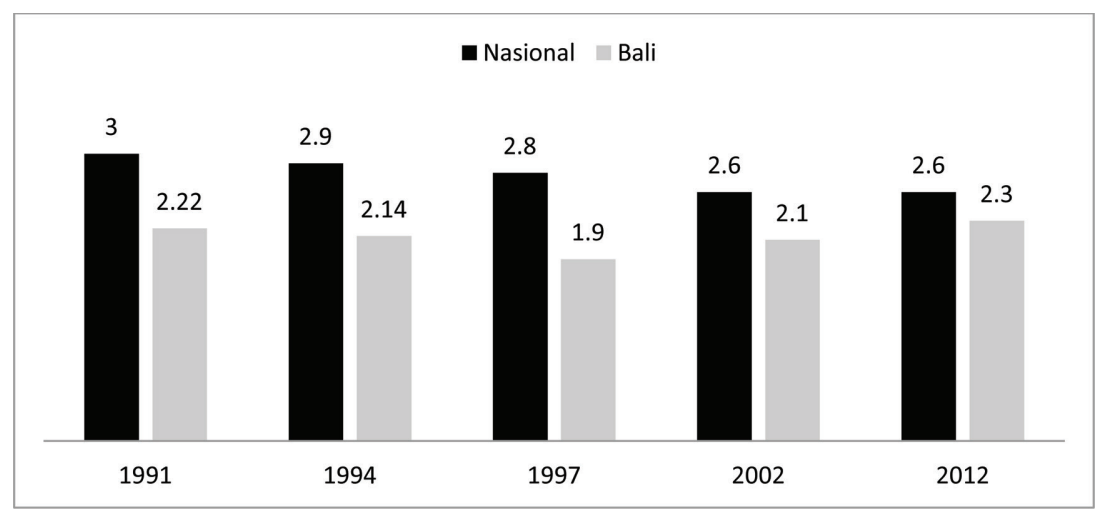

Gambar 3 TFR secara Nasional dan Bali, 1991-2012

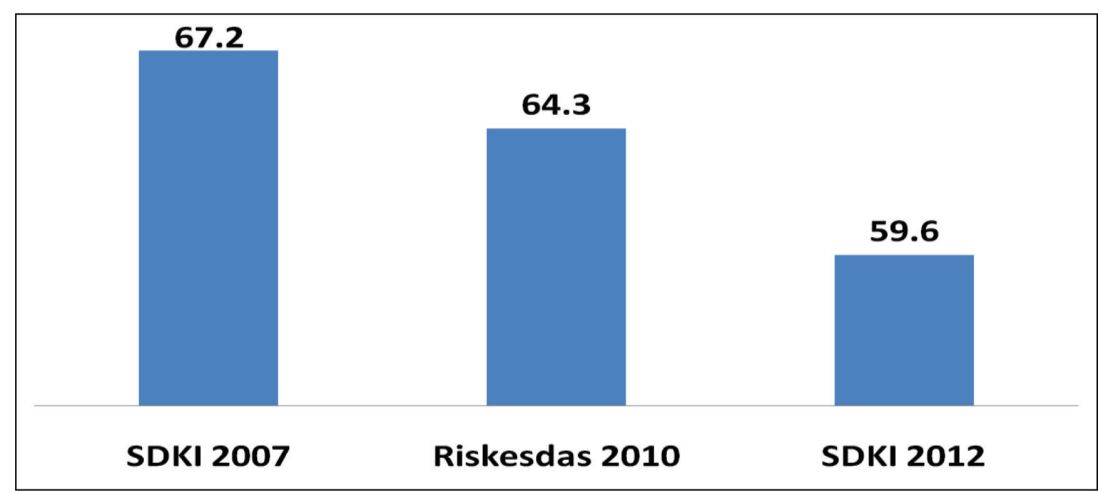

Gambar 4 Persentase wanita usia subur yang sedang mempergunakan kontrasepsi modern tahun 2007, 2010 dan 2012, Provinsi Bali

pertumbuhan penduduk di Bali juga disebabkan karena meningkatnya tingkat kelahiran. Meningkatnya tingkat kelahiran disebabkan karena menurunnya pemakai kontrasepsi (peserta $\mathrm{KB}$ ), berkurangnya pemakai kontrasepsi jangka panjang dan meningkatnya tingkat kelahiran pada wanita usia remaja.

Data yang belum tersedia saat ini, baik dari hasil SDKI maupun survei atau penelitian lainnya adalah perbedaan TFR dan pemakaian kontrasepsi pada penduduk migran di Bali dan penduduk lokal. Dengan demikian belum bisa diketahui apakah peningkatan TFR terjadi pada penduduk migran, penduduk lokal, atau pada kedua kelompok tersebut. Bila dilihat hasil Survei Kesehatan dan Demografi tahun 2012, rata-rata jumlah anak yang diinginkan oleh PUS di Bali masih tetap dengan kondisi 10 tahun yang lalu yaitu 2 anak. Data ini menunjukkan bahwa pada dasarnya di Bali tidak lagi diperlukan adanya edukasi atau kampanye tentang keluarga kecil karena mereka telah menginginkan hanya 2 anak. Menurunnya pemakai kontrasepsi dan bekurangnya pemakai kontrasepsi jangka panjang besar kemungkinannya karena kurang optimalnya pelayanan kontrasepsi dan adanya masalah kelembagaan yang menangani dan yang bertanggung jawab terhadap masalah ini. BKKBN Provinsi adalah lembaga vertikal yang bertanggung jawab kepada BKKBN Pusat. Sesuai dengan tugas dan fungsinya, BKKBN tidak mempunyai tugas pelayanan kontrasepsi melainkan untuk menumbuhkan demand masyarakat agar mengikuti program KB (terutama memakai kontrasepsi). Demikian pula Biro Kesra Provinsi Bali tidak mempunyai tugas untuk memberi atau melakukan supervisi pada tempat-tempat pelayanan kontrasepsi. Satuan Kerja Perangkat Daerah (SKPD) yang seharusnya melakukan fungsi tersebut adalah Dinas Kesehatan Provinsi Bali.

Akan tetapi, dalam struktur organisasi Dinas Kesehatan Provinsi Bali, tidak ada bagian atau seksi yang bertanggung jawab untuk urusan keluarga berencana. Tiga sasaran dan indikator kunci dalam Program KB adalah: a) menurunnya TFR, b) meningkatnya prevalensi pemakai kontrasepsi dan c) meningkatnya pemakai kontrasepsi jangka panjang.

Muncul kesulitan ketika meletakkan tiga sasaran dan indikator kunci ini dalam penyusunan rancangan Rencana Pembangunan Jangka Menengah Daerah (RPJMD) Provinsi Bali, karena BKKBN bukan Satuan Kerja Perangkat (SKPD), Biro Kesra tidak mempunyai fungsi dan kemampuan untuk melaksanakan sasaran tersebut sedangkan Dinas Kesehatan tidak mempunyai struktur untuk tugas tersebut. Dengan demikian, ada kekosongan kelembagaan atau tidak ada penanggung jawab dalam hal urusan yang amat vital ini di Provinsi Bali. Fenomena ini kemungkinan juga terjadi di provinsi lain dan karena itu secara nasional TFR dan pemakaian kontrasepsi juga mengalami stagnasi.

\section{REKOMENDASI}

1. Untuk mengurangi arus migrasi masuk dari luar Bali, satu-satunya cara adalah dengan membuat peraturan tata ruang yang amat rinci (detail tata ruang) di kabupaten/kota dan menerapkannya dengan intensif dan konsisten.

2. Untuk bisa menerapkan peraturan detail tata ruang secara konsisten maka diperlukan anggaran pengawasan yang lebih besar sehingga bisa dilaksanakan tindakan pencegahan sebelum terjadi pelanggaran tata ruang. Menanggulangi pelanggaran yang sudah terjadi akan jauh lebih pelik dibanding mencegah sebelum terjadinya pelanggaran.

3. Untuk mengurangi arus urbanisasi, satusatunya solusi adalah dengan menyebarkan sentra-sentra kegiatan ekonomi di kawasan/ kabupaten lain dan pengembangan ekonomi pedesaan. 
4. Untuk menurunkan tingkat kelahiran (TFR) dan meningkatkan pemakaian kontrasepsi terutama yang jangka panjang (tubektomi, vasektomi, IUD dan implan), langkah awal yang diperlukan adalah menetapkan SKPD (lembaga) yang bertanggung jawab dan mempunyai kompetensi untuk urusan ini. Satu-satunya SKPD yang memenuhi kriteria ini adalah dinas kesehatan karena mereka yang mempunyai jaringan dengan seluruh rumah sakit, puskesmas dan klinik-klinik KB swasta. BKKBN bisa tetap fokus dalam upaya-upaya peningkatan demand dan Biro Kesra agar lebih fokus dalam fungsi koordinasi dan perumusan kebijakan saja.

5. Demand masyarakat Bali untuk memilih cara tubektomi cukup tinggi dan untuk "menangkap" peluang (unmet need) tersebut amat diperlukan layanan fast tract (jalur cepat), one day care, nyaman, aman dan dengan biaya yang terjangkau.

6. Diperlukan penelitian untuk mengetahui perbedaan TFR dan pola pemakaian kontrasepsi pada penduduk migran dan penduduk lokal sehingga program dan jenis pelayanan bisa dikhususkan pada masing-masing kelompok tersebut. Misalnya, bila penduduk migran lebih memilih implan (KB Susuk), maka perlu disediakan pelayanan kontrasepsi jenis ini di daerah-daerah pemukiman mereka.

\section{DAFTAR PUSTAKA}

1. Badan Pusat Statistik Provinsi Bali. Menuju Era Baru Kependudukan Provinsi Bali; Analisis Profil Kpendudukan Provinsi Bali (Hasil SP2010). Denpasar: BPS; 2011.

2. Badan Pusat Statistik. Laju Pertumbuhan Penduduk Menurut Provinsi. [cited 2013 October 15]. Available from URL: http://www.bps.go.id/tab?sub/ view.php

3. Badan Pusat Statistik, Badan Kependudukan dan Keluarga Berencana Nasional, Kementerian Kesehatan. Survei Demografi dan Kesehatan Indonesia Tahun 2012. Jakarta; 2013.

4. Badan Penelitian dan Pengembangan Kesehatan Departemen Kesehatan RI. Laporan Nasional Riset Kesehatan Dasar (Riskesdas) Tahun 2010. Jakarta; 2010.

5. Wirawan, DN. Penelitian Pengembangan dengan Sistem Moduler, Suatu Penelitian tentang Ciri-Ciri Sosial Ekonomi, Keluarga Berencana, Fertilitas, Kesehatan dan Kelangsungan Pemakaian Alat Kontrasepsi di Bali, 1982. Denpasar: Bagian Ilmu Kesehatan Masyarakat, Fakultas Kedokteran Universitas Udayana/Badan Koordinasi Keluarga Berencana Nasional Provinsi Bali; 1984.

6. Wirawan, DN. Survei Perilaku Rumah Tangga Tahun 1985 Provinsi Bali. Denpasar: Bagian Ilmu Kesehatan Masyarakat, Fakultas Kedokteran Universitas Udayana/ Badan Koordinasi Keluarga Berencana Nasional Provinsi Bali; 1986.

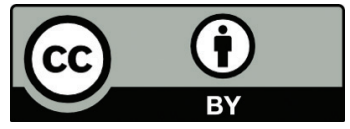

This work is licensed under a Creative Commons Attribution 